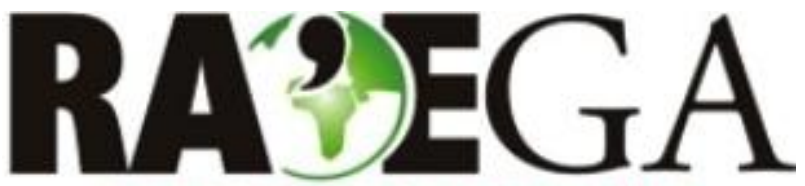

O ESPACO GEOGRAFICO EM ANÁLISE

\title{
CLASSIFICAÇÃO DA PAISAGEM DO BAIRRO DO BACACHERI (CURITIBA, PARANÁ) COM BASE NA COBERTURA DO SOLO
}

\section{LANDSCAPE CLASSIFICATION OF BACACHERI DISTRICT (CURITIBA/PARANÁ) BASED ON LAND COVER}

\author{
Mariana Andreotti Dias \\ Graduanda do curso de Geografia pela Universidade Federal do Paraná (UFPR) \\ Departamento de Geografia \\ Curitiba, $P R$ \\ e-mail: mariana_andreotti_d@hotmail.com \\ João Carlos Nucci \\ Professor da Universidade Federal do Paraná (UFPR) \\ Departamento de Geografia \\ Curitiba, $P R$ \\ e-mail:nucci@ufpr.br \\ Simone Valaski \\ Professora da Universidade Federal do Paraná (UFPR) \\ Setor de Educação Profissional e Tecnológica \\ Curitiba, $P R$ \\ e-mail: simonevalaski@ig.com.br
}

Recebido em: 08/05/2014

Aceito em: 08/06/2014

\section{Resumo}

O intenso adensamento populacional e de edificações, associado a diminuição da vegetação concorrem para a queda da qualidade ambiental dos centros urbanos. Porém, é importante que se reconheça que o nível de desenvolvimento de uma sociedade se configura conforme a capacidade de preservação e respeito a natureza onde o ordenamento do espaço é primordial. Foi aplicado um método de classificação da cobertura do solo que considera a estrutura da paisagem e executa inferências quanto à sua dinâmica relacionada a qualidade ambiental. A área teste foi o bairro do Bacacheri (Curitiba, Paraná), pois o mesmo já apresenta um levantamento semelhante realizado com base em fotografias aéreas de 2001, o que permitiu uma comparação temporal. O levantamento foi feito com base em imagens de satélite (Google Earth) nas escalas entre 1:5.000 e 1:3.000 e do ano 2010. Para o mapeamento e o tratamento dos dados foram utilizadas as ferramentas do software ARCGIS 10.1 da ESRI. Concluiu-se que o bairro perdeu 46,9ha de vegetação arbustiva e herbácea em apenas oito anos, e que apesar de ainda manter uma boa qualidade ambiental, em comparação com algumas cidades alemãs, corre o risco de 
uma intensificação da ocupação do solo por edificações, o que acarretaria em uma diminuição dessa qualidade.

Palavras-chave: Uso da terra, adensamento urbano, qualidade ambiental.

\begin{abstract}
The intense densification of population and building associated with decrease of vegetation contribute to the fall of the environmental quality of urban centers. However, it is important to recognize that the level of development of a society is configured according to the ability to preserve and respect nature where spatial planning is paramount. It was applied a method of land cover classification that consider the landscape structure and execute inferences over its dynamic related with the environmental quality. The Bacacheri district (Curitiba, PR) was chosen as the test area because it already has a similar survey based on aerial photographs of 2001. This fact allowed a temporal comparison. The survey was based on satellite images (Google Earth), in scales between 1:5.000 e 1:3.000, 2010. The mapping and the data processing were made using the tools of the software ARCGIS 10.1 by ESRI. It was conclude that the district had lost 46,9ha of the shrub and herbaceous vegetation in just eighty years. Although the district still has a good environmental quality, comparing with some German cities, it runs the risk of intensified occupation of land by buildings, which would result in a decrease of this quality.
\end{abstract}

Keywords: Land use, urban densification, environmental quality.

\title{
INTRODUÇÃO
}

A intensificação da ocupação dos espaços urbanos por edificações é o principal modelo seguido pelos setores de planejamento das prefeituras dos municípios brasileiros em conivência com os interesses da indústria de construções e dos grandes proprietários de lotes.

Segue-se, a esse modelo, um outro, que necessariamente acaba tendo que socorrer as cidades devido às consequências do adensamento desmensurado de edificações e de população, ou seja, o das obras viárias, de controle de enchentes, de infraestrutura de transporte, entre outros.

Os espaços não edificados passam, cada vez mais, a dar lugar a grandes edifícios, que impermeabilizam praticamente toda superfície do solo, permitindo a existência de uma vegetação implantada em pequenas áreas e sobre laje, devido às garagens subterrâneas, capaz de exercer a função estética porém com menor importância em relação às funções ecológica ede lazer. (NUCCl, 1999).A consequência desse tipo de evolução das paisagens urbanas é a diminuição 
paulatina da qualidade ambiental e o aumento da dependência de energia (fóssil e hidrelétrica) e de tecnologia para o bom funcionamento das paisagens, afastandoas, cada vez mais, do funcionamento próximo ao da natureza, ou seja, tornando as cidades cada vez mais insustentáveis. (BELEM e NUCCI, 2011)

De acordo com Nucci (1998), a qualidade ambiental urbana é um dos principais temas em um tipo especial de planejamento em vigor na Alemanha desde a década de 1970, conhecido como Planejamento da Paisagem.

O Planejamento da Paisagem se apresenta como um instrumento de ordenamento do uso do espaço (urbano ou não) considerando-se a sua proteção ambientallevando em conta perspectivas da Ecologia. A classificação da paisagem entra como um procedimento fundamental desse instrumento que também valoriza a participação popular em todo o processo. (KIEMSTED, et al, 1998; NUCCI, 2007).

Até os primeiros anos do século XIX, o Planejamento da Paisagem na Alemanha trazia apenas uma preocupação estética, porém, com as repercussões da Revolução Industrial as preocupações também com a qualidade do meio físico ganharam força pela necessidade de ordenamento do caótico crescimento urbano. Já no pós Segunda Guerra Mundial a necessidade de reconstrução das cidades também forneceu campo para a atuação do Planejamento da Paisagem, mas agora com uma conotação ecológica, considerando além das questões estéticas da paisagem, a proteção das funções da natureza, mesmo nas áreas urbanizadas. (KIEMSTED, et al, 1998).

Passando, ao longo do tempo, por diversas discussões acerca dos objetivos do Planejamento da Paisagem, chega-se a 1986 ao conceito de instrumento da proteção e desenvolvimento da natureza com o objetivo de salvaguardar a capacidade dos ecossistemas e o potencial recreativo da paisagem como partes fundamentais para a vida humana. (NUCCl, 1998).

No Planejamento da Paisagem, exigido por lei na Alemanha, a participação popular é fundamental, assim, uma das questões levadas em consideração é a qualidade da informação disponibilizada para o acompanhamento do cidadão interessado.

Infelizmente, no Brasil, é muito mais difícil para ocidadão acompanhar e ter 
alguma noção do que acontece com a sua cidade em termos de tipos, distribuição e quantificação de espaços, e, consequentemente, poder opinar sobre a qualidade ambiental urbana.

VALASKI (2013) constatou que sites das prefeituras de algumas cidades alemãs pesquisadas são muito mais eficientes na transmissão de informações sobre a cobertura e o uso do solo urbano do que foi encontrado no site da Prefeitura do Município de Curitiba (Pr).

Apesar do acesso à informação estar cada vez mais facilitado, principalmente devido à internet, o cidadão comum ainda apresenta dificuldades no entendimento do funcionamento dessa nova linguagem e não consegue aproveitar de modo satisfatório, por exemplo, nem mesmo as imagens aéreas de sua cidade disponibilizadas pelo Google.

Como uma forma de facilitar o acesso do cidadão a essas informações para que ele possa participar do desenvolvimento de sua cidade, Valaski (2013) desenvolveu um método de interpretação das paisagens urbanizadas visualizadas no Google Earth e baseado em uma tríade "qualidade ambiental urbana classificação e interpretação da cobertura do solo - participação popular".

Este trabalho tem por objetivo o de apresentar uma classificação das unidades de paisagem do bairro do Bacacheri (Curitiba, Paraná), com base no método de Valaski (2013), ou seja, com base nas diferentes classes de cobertura do solo ${ }^{1}$, procurando corroborar o fato de que o planejamento dos espaços é possível de uma maneira menos complexa e mais acessível à população. Os resultados encontrados, para o ano de 2010, também foram comparados aos de Pivetta et al. (2005) com o propósito de apresentar mais uma possibilidade, a de monitoramento pelos cidadãos, dos valores identificados.

\section{REVISÃO BIBLIOGRÁFICA}

A proximidade com a natureza gera benefícios para a saúde humana e, segundo Caput do Artigo 225 da Constituição Federal brasileira, de 1988, trata-se de um direito da população: "Todos têm direito ao meio ambiente ecologicamente equilibrado, bem de uso comum do povo e essencial à sadia qualidade de vida,

\footnotetext{
${ }^{1} \mathrm{O}$ uso do solo não foi considerado na análise, mas apenas a cobertura do solo.
} 
impondo-se ao Poder Público e à coletividade o dever de defende-lo e preservá-lo para as presentes e futuras gerações." (BRASIL, 1988)

Uma das mais eficientes formas de se preservar um ambiente urbano com qualidade seria por meio do planejamento da ocupação do solo, principalmente, com o provimento de Espaços de Uso Público, Livres de Edificação e com Vegetação - EUPLEVs, em todas as partes do município. (BUCCHERI FILHO, 2012; TONETTI, et al., 2012; BUCCHERI FILHO e NUCCI, 2006)

Para Jackson (2003), há fortes argumentos relativos à saúde pública para a incorporaçãodo verde, de luz natural e acesso visual e físico aos espaços livres verdes perto dasresidências e em outros pontos da cidade.

Não somente a falta de vegetação, mas também a intensificação das superfícies impermeabilizadas, seja por edificações ou simples pavimentação, como asfalto, pode fortemente afetar a qualidade ambiental dasáreas urbanas por estar correlacionada com llha Térmica, aumento do run-off e perda dehabitats naturais para a vida selvagem. As leis alemãs ligadas ao planejamento têmpermitido impermeabilizar somente o necessário. (PAULEIT eDUHME, 2000)

Não se sabe ao certo a quantidade de espaços não edificados que seria necessária para a manutenção de uma boa qualidade ambiental urbana, pode-se dizer que devido às diferentes caraterísticas físicas e culturais nem mesmo se consiga um único valor que possa ser satisfatório para todas as diferentes paisagens, sendo assim, uma aproximação poderia ser feita por meio de comparações entre cidades.

No Atlas Ambiental de Berlim, documento de qualidade disponibilizado gratuitamente na internet pela Prefeitura de Berlim para que todos os cidadãos possam acompanhar democraticamente o que acontece com a sua cidade, podese encontrar dados sobre os tipos de usos do solo de algumas cidades da Alemanha (Tabela 1). 


\section{CLASSIFICAÇÃO DA PAISAGEM DO BAIRRO DO BACACHERI \\ (CURITIBA, PARANÁ) COM BASE NA COBERTURA DO SOLO}

Tabela 1: Uso da terra em diferentes cidades da Alemanha.

\begin{tabular}{|c|c|c|c|c|c|c|c|c|}
\hline Uso & Berlin & Hamburg & Munich & Cologne & Frankfurt & Hanover & Média & Média \\
\hline Água & 6 & 8 & 1 & 5 & 2 & 3 & 4 & \multirow{4}{*}{$\begin{array}{c}\text { Espaços } \\
\text { Não } \\
\text { edificados } \\
(47 \%)\end{array}$} \\
\hline Floresta & 18 & 4 & 5 & 14 & 15 & 11 & 11 & \\
\hline Agricultura & 7 & 30 & 18 & 22 & 28 & 19 & 21 & \\
\hline $\begin{array}{l}\text { Parque e } \\
\text { cemitério }\end{array}$ & 11 & 4 & 12 & 10 & 15 & 14 & 11 & \\
\hline Edificações & 43 & 34 & 40 & 32 & 25 & 33 & 35 & \multirow{2}{*}{$\begin{array}{l}\text { Espaços } \\
\text { Edificados } \\
(39 \%)\end{array}$} \\
\hline Misto & 3 & 8 & 7 & 2 & 0 & 6 & 4 & \\
\hline Sist. viário & 12 & 12 & 17 & 15 & 14 & 15 & 14 & $(14 \%)$ \\
\hline
\end{tabular}

Fonte: Berlim (2001) e Pivetta, et al (2005). Adaptação: os autores, 2014.

Em termos gerais pode-se afirmar, com base na Tabela 1 e por anotações em sala de aula do Professor Felisberto Cavalheiro², que as cidades da Alemanha procuram manter uma média de $40 \%$ de espaços não edificados, $40 \%$ de espaços edificados e $20 \%$ para o sistema de espaços viários.

Assim, apenas para se ter uma ideia comparativa, no distrito de Santa Cecília (bairro central do município de São Paulo), Nucci (1998) encontrou apenas $2 \%$ da área do distrito ocupados por espaços livres públicos. No caso, esses espaços eram livres de edificações, porém, de uso público, um critério um pouco mais restritivo. Todavia, o valor é tão distante dos encontrados nas cidades alemãs, que mesmo sem essas restrições a quantidade seria ainda bem inferior.

Um monitoramento desses espaços valiosos para a qualidade ambiental urbana também deveria ser feito, pelo setor público e pela população.

Segundo Sukoppet al. (1979), as áreas centrais densamente construídas de Berlim estavam cobertas com $32 \%$ por vegetação. Na tabela 1, identifica-se que em 1991 Berlim estava com 36\% de sua área coberta por vegetação (floresta, agricultura, parques e cemitérios), fato que demonstra a preocupação dos planejadores alemães com essas questões.

\footnotetext{
${ }^{2}$ O doutor Felisberto Cavalheiro (1945-2003), foi professor do Departamento de Geografia (FFLCHUSP) e transitava muito bem pelas diferentes áreas que tratam da questão ambiental, entre elas a Geografia, a Ecologia, a Agronomia e a Arquitetura. Segundo seu orientador na Alemanha, Prof. Dr. Gert Gröning, "(...) ele pode ser considerado o pioneiro da cultura de jardins e do planejamento de espaços livres no Brasil." (GRÖNING, 2009 p. 16)
} 


\section{MÉTODO}

Com uma população de 23.734 habitantes (IPPUC, 2013), o bairro do Bacacheri localiza-se a 3.140 metros a nordeste do marco zero de Curitiba; apresenta área total de 698,10 hectares e está totalmente inserido na sub-bacia do Rio Bacacheri, afluente do rio Atuba. Os bairros limitrofes a ele são: Boa Vista, Tingui, Bairro Alto, Jardim Social, Cabral, Hugo Lange e Santa Candida. (Figura 1).
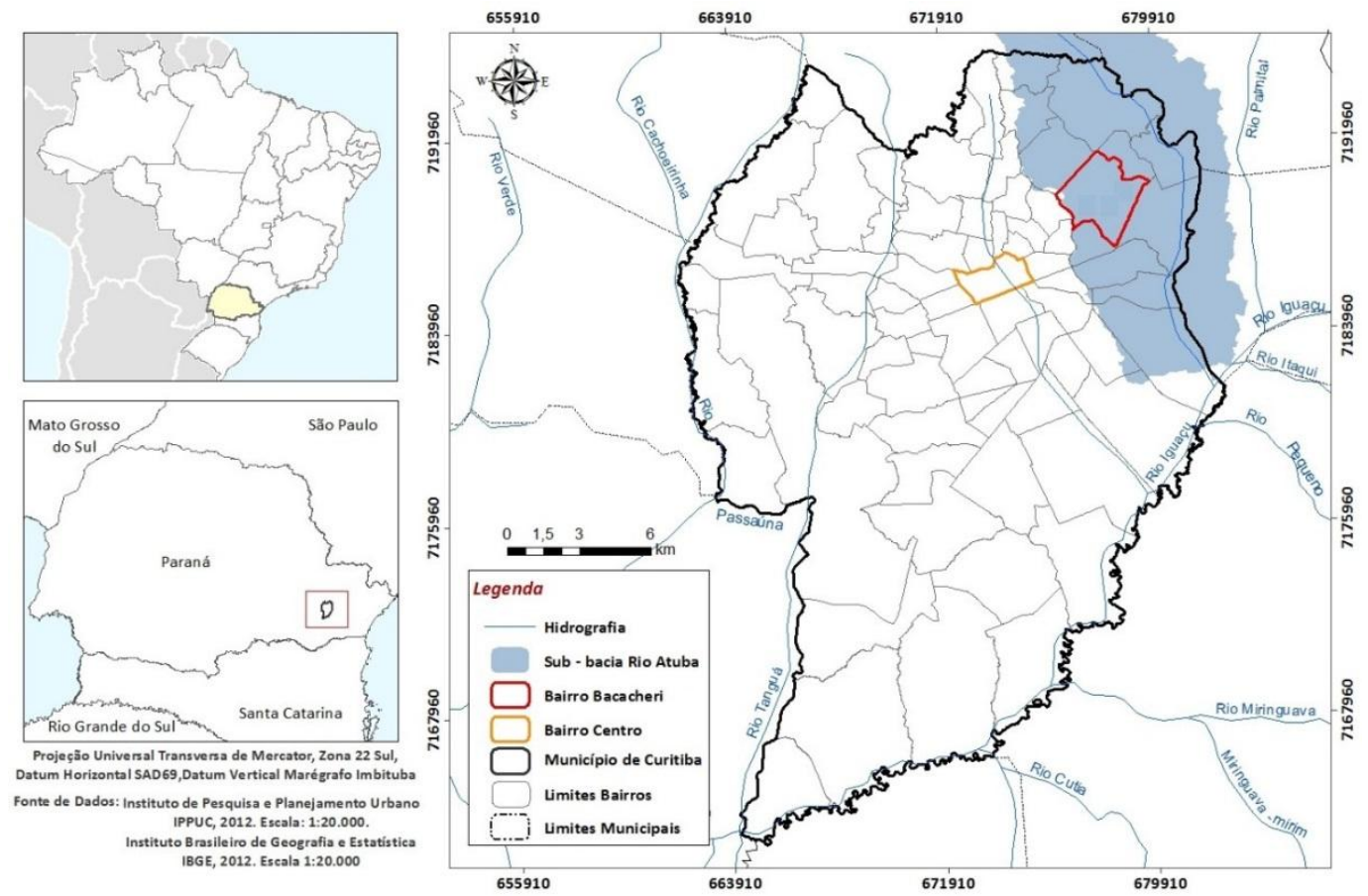

Figura 1: Mapa de localização do bairro Bacacheri, Curitiba - PR.

A classificação das paisagens do bairro foi realizada de acordo com o método proposto por Valaski (2013) que desenvolveu uma chave classificatória das paisagens em um perfil norte-sul do município de Curitiba, com base em imagens de satélite (Google Earth) em escala da ordem de 1:5.000.

No mapeamento do bairro do Bacacheri foram utilizadas imagens de satélite fornecida pelo Google (2010), com escalas aproximadas de 1:5.000 e 1:3.000, o arruamento fornecido pelo IPPUC do ano de 2010, escala 1:10.000. Para a realização dos procedimentos o software utilizado foi o ARCGIS 10.1 da ESRI e o mapa final está apresentado na escala 1:14.000.

Durante o processo de elaboração do mapa a imagem aérea do Google apresentou áreas que sofreram modificações de 2010 para cá. Dessa forma o uso do Google Street View, imagens de 2011, possibilitou um mapeamento mais 


\section{CLASSIFICAÇÃO DA PAISAGEM DO BAIRRO DO BACACHERI \\ (CURITIBA, PARANÁ) COM BASE NA COBERTURA DO SOLO}

preciso e atualizado.

\section{RESULTADOS E DISCUSSÃO}

Os resultados obtidos foram o mapa de cobertura da terra, na escala 1:14.000 (Figura2), a tabela 2 com a quantificação das áreas de cada classe de cobertura da terra e a chave classificatória ou o quadro-legenda com a explicação detalhada dos tipos de unidades de paisagens encontrados bem como as inferências quanto a dinâmica de cada paisagem (Figuras 3a a 3e).

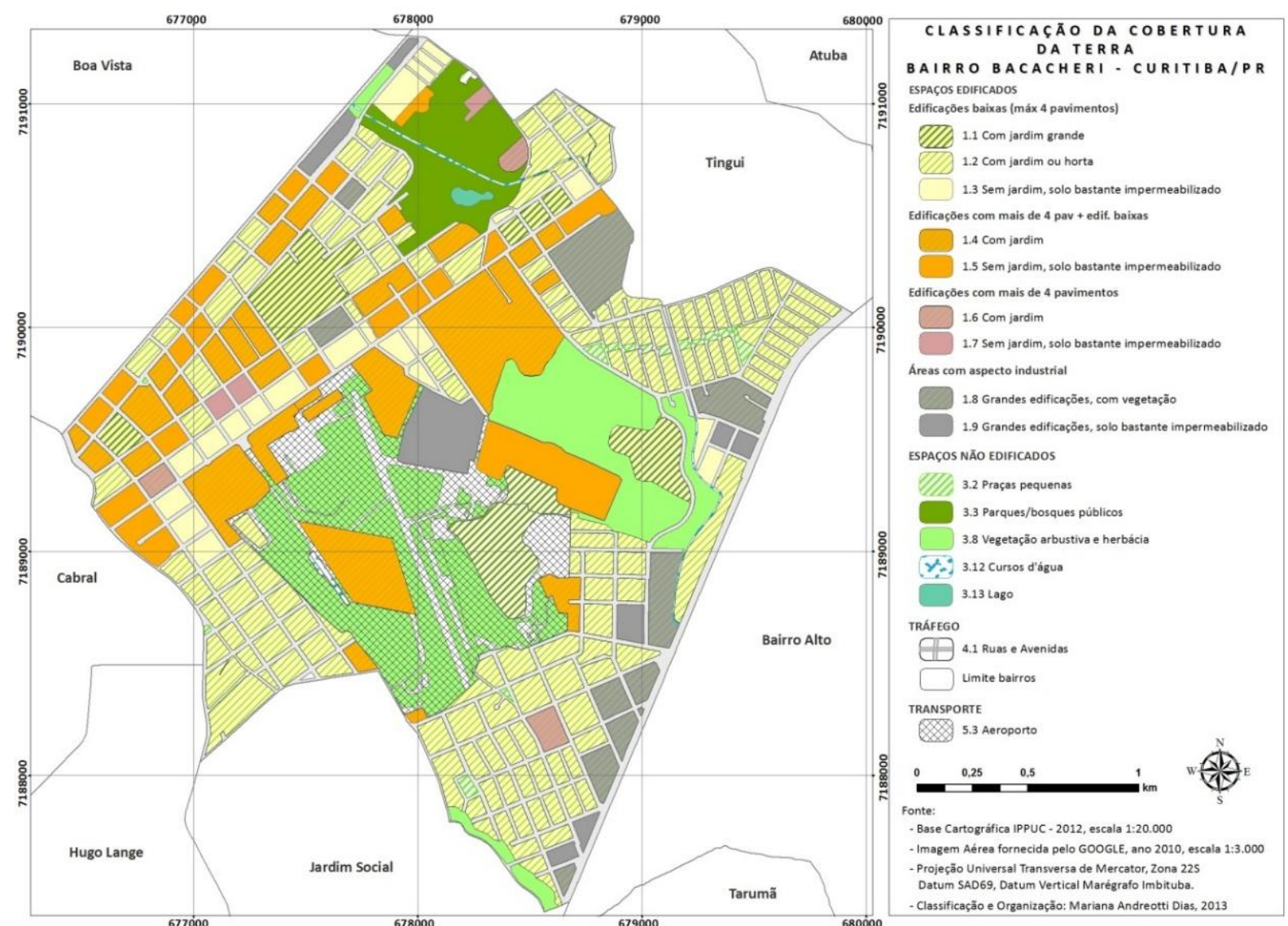

Figura 2: Mapa da cobertura da terra do bairro Bacacheri, Curitiba $-{ }^{6780000}$ PR. 


\section{CLASSIFICAÇÃO DA PAISAGEM DO BAIRRO DO BACACHERI}

(CURITIBA, PARANÁ) COM BASE NA COBERTURA DO SOLO

Tabela 2: Quantificação das classes de cobertura da terra do bairro Bacacheri (Curitiba. Paraná).

\begin{tabular}{|c|c|c|c|}
\hline Espaços & Classes de cobertura da terra & (ha) & $\%$ \\
\hline \multirow{12}{*}{ 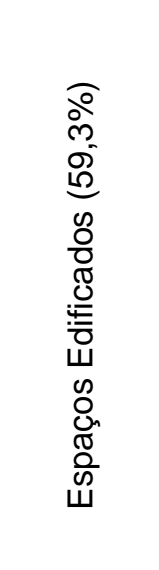 } & Edificações baixas (máximo 4 pavimentos) & & \multirow{5}{*}{36,1} \\
\hline & 1.1 Com jardim grande & 46,6 & \\
\hline & 1.2 Com jardim ou horta & 178,4 & \\
\hline & 1.3 Sem jardim, solo bastante impermeabilizado & 26,7 & \\
\hline & Edificações com mais de 4 pavimentos + edificações & & \\
\hline & $\underline{\text { baixas }}$ & & \multirow{3}{*}{15,1} \\
\hline & 1.4 Com jardim & 77,0 & \\
\hline & $\begin{array}{l}1.5 \text { Sem jardim, solo bastante impermeabilizado. } \\
\text { Edificacões com mais de } 4 \text { pavimentos }\end{array}$ & 28,4 & \\
\hline & 1.6 Com jardim & 3,6 & \multirow[t]{2}{*}{0,8} \\
\hline & $\begin{array}{l}1.7 \text { Sem jardim, solo bastante impermeabilizado. } \\
\text { Áreas com aspecto industrial }\end{array}$ & 2,0 & \\
\hline & 1.8 Grandes galpões, com vegetação & 32,0 & \multirow{2}{*}{7,3} \\
\hline & $\begin{array}{l}1.9 \text { Grandes galpões, com solo bastante } \\
\text { impermeabilizado. }\end{array}$ & 19,1 & \\
\hline \multirow{5}{*}{ 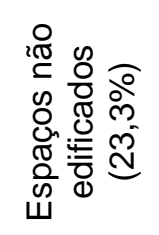 } & 3.2 Praças pequenas & 3,5 & 0,5 \\
\hline & 3.3 Parque/ bosque público & 15,2 & 2,2 \\
\hline & 3.8 Vegetação arbustiva e herbácea & 96,1 & 13,8 \\
\hline & 3.12 Cursos d'água & 2,6 & \multirow{2}{*}{0,5} \\
\hline & 3.13 Lago & 1,0 & \\
\hline \multirow{3}{*}{$\begin{array}{c}\text { Espaço } \\
\text { viário } \\
(17,4 \%)\end{array}$} & 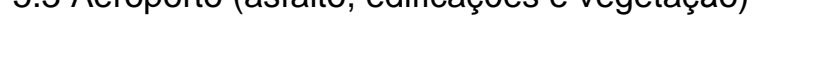 & & 0,0 \\
\hline & 4.1 Ruas e Avenidas & 121,7 & 17,4 \\
\hline & Total & 698,0 & 100 \\
\hline
\end{tabular}


DIAS, M.A.; NUCCI, J.C.; VALASKI, S.

\section{CLASSIFICAÇÃO DA PAISAGEM DO BAIRRO DO BACACHERI \\ (CURITIBA, PARANÁ) COM BASE NA COBERTURA DO SOLO}

- ESPAÇOS NÃO EDIFICADOS

Edificações baixas (máximo 4 pavimentos)
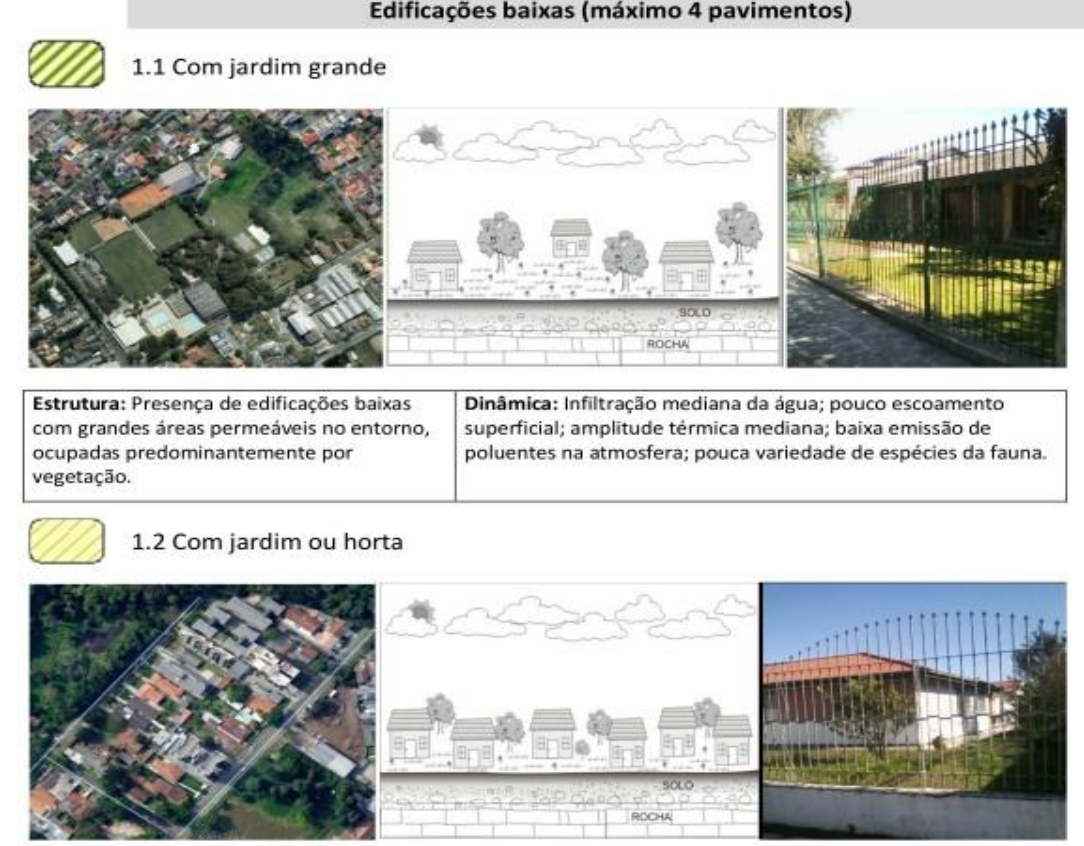

Estrutura: Presença de edificações baixas com $\quad$ Dinâmica: pouca infiltração de água de chuva, aumento do

$\begin{array}{lll}\text { áreas permeáveis ocupadas por jardim ou horta, } & \text { escoamento superficial, aumento da amplitude térmica, baixa } \\ \text { com vegetaçăo nos estratos arbórea, arbustivo e } & \text { emissão de poluentes na atmosfera, menor variedade de }\end{array}$ com vegetaçăo nos estratos arbórea, arbustivo e herbáceo. espécies da fauna.

1.3 Sem jardim, solo bastante impermeabilizado

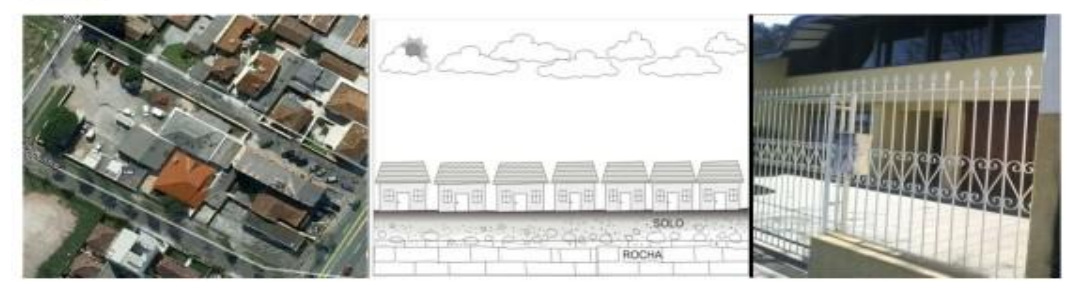
\begin{tabular}{|l|l|}
\hline $\begin{array}{l}\text { Estrutura: Edificações baixas com pouco ou nenhum } \\
\text { espaço destinado para jardim ou horta. A vegetação é } \\
\text { praticamente inexistente. Solo intensamente } \\
\text { impermeabilizado. }\end{array}$ & $\begin{array}{l}\text { Dinâmica: infiltraçăo da água da chuva quase inexistente; } \\
\text { alto escoamento superficial; alta amplitude térmica; } \\
\text { baixa emissão de poluentes na atmosfera; quase } \\
\text { inexistência de espécies da flora e fauna. }\end{array}$ \\
\hline
\end{tabular}

Figura 3a: Chave classificatória com inferências. 


\section{CLASSIFICAÇÃO DA PAISAGEM DO BAIRRO DO BACACHERI (CURITIBA, PARANÁ) COM BASE NA COBERTURA DO SOLO}

\section{Edificações com mais de 4 pavimentos + edificações baixas}

1.4 Com Jardim

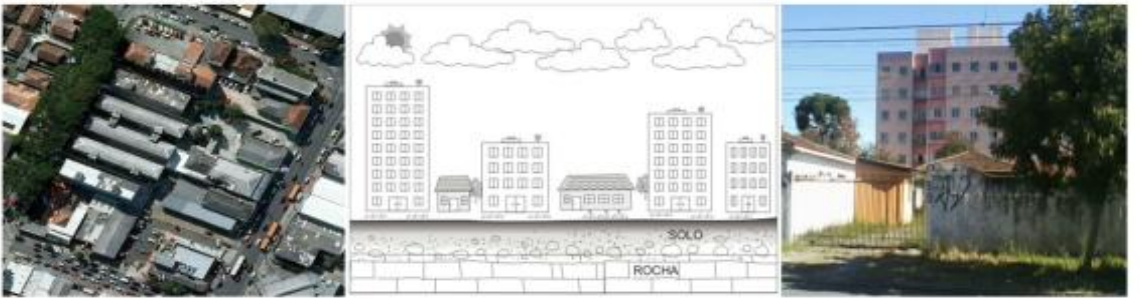

Estrutura: Edificaçōes com mais de 4 pavimentos associadas com edificaçōes baixas. Presença de alguns espaços ocupados por vegetação arbórea arbustiva e/ou herbácea. A maior parte do solo é impermeável.

Dinâmica: infiltração da água da chuva quase inexistente: alto escoamento superficial; alta amplitude térmica; alta emissāo de poluentes na atmosfera pelo aumento do tráfego de veículos; quase inexistência de espécies da fauna.

1.5 Sem jardim, solo bastante impermeabilizado
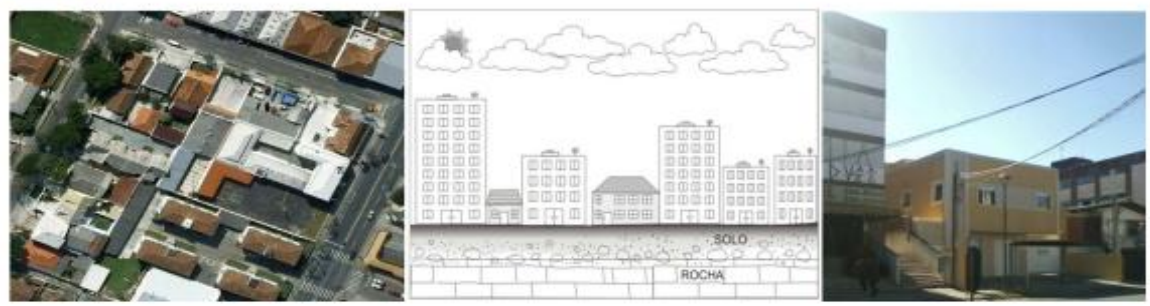

\begin{tabular}{|l|l|}
\hline Estrutura: Edificações com mais de 4 & Dinâmica: infiltração da água da chuva inexistente; altíssimo \\
pavimentos associadas com edificaçő́es & escoamento superficial; altíssima amplitude térmica; aumento na \\
baixas. A vegetação é quase inexistente. As As & emissão de poluentes na atmosfera pelo aumento do tráfego de \\
áreas permeáveis são praticamente & $\begin{array}{l}\text { veículos; quase inexistência de espécies da fauna e flora; aumento do } \\
\text { gasto de energia para a manutenção das edificaçốes. }\end{array}$ \\
\hline inexistentes &
\end{tabular}

Edificações com mais de 4 pavimentos

1.6 Com jardim
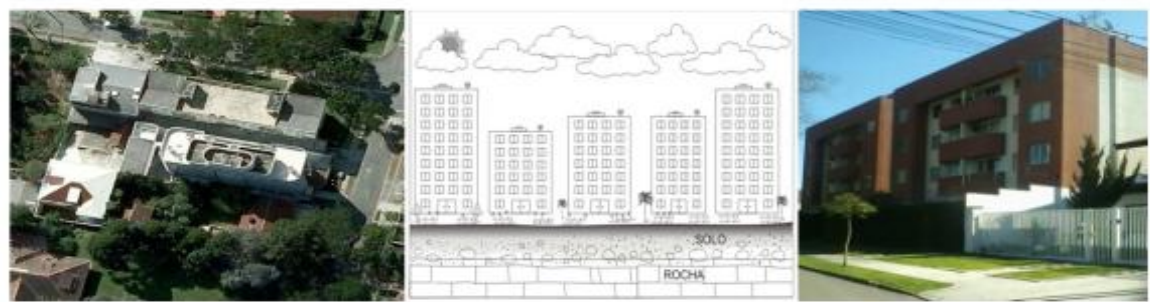

Estrutura: Edificações com mais de 4 pavimentos com presença de alguns espaços ocupados por jardim, com vegetação arbórea, arbustiva $\mathrm{e} / \mathrm{ou}$

Dinåmica: pouca infiltração da água de chuva; diminuição do escoamento superficial; diminuição da amplitude térmica; alta emissão de poluentes na atmosfera pelo tráfego de veículos; pouca herbácea. variedade de espécies da fauna; alto gasto de energia para a manutenção das edificaçōes.

Figura 3b: Chave classificatória com inferências. 


\section{CLASSIFICAÇÃO DA PAISAGEM DO BAIRRO DO BACACHERI (CURITIBA, PARANÁ) COM BASE NA COBERTURA DO SOLO}

1.7 Sem jardim, solo bastante impermeabilizado

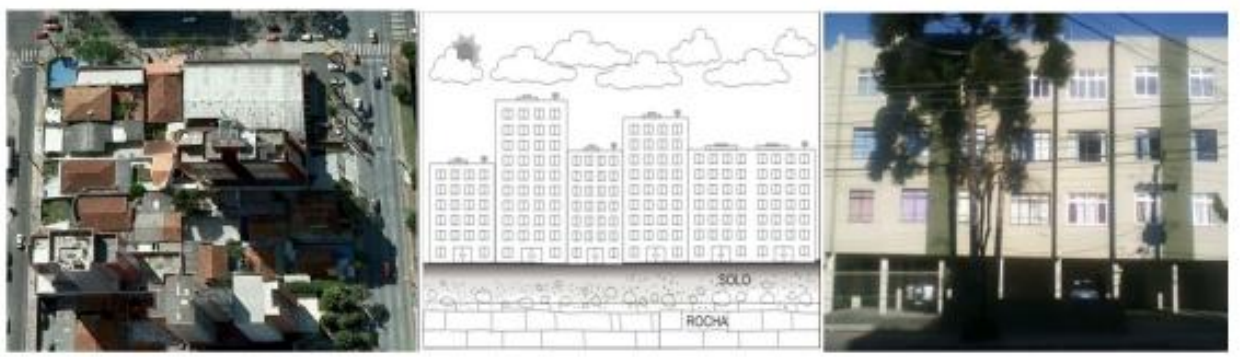

Estrutura: Edificações com mais de 4 pavimentos sem presença de vegetação. As áreas permeáveis são praticamente inexistentes.

Dinâmica: infiltração da água da chuva inexistente; altíssimo escoamento superficial; altíssima amplitude térmica; alta emissão de poluentes na atmosfera pelo tráfego de veiculos; quase inexistência de espécies da fauna e flora; alto gasto de energia para a manutençăo das edificaçőes.

\section{Áreas com aspecto industrial}

1.8 Grandes galpões, com vegetação
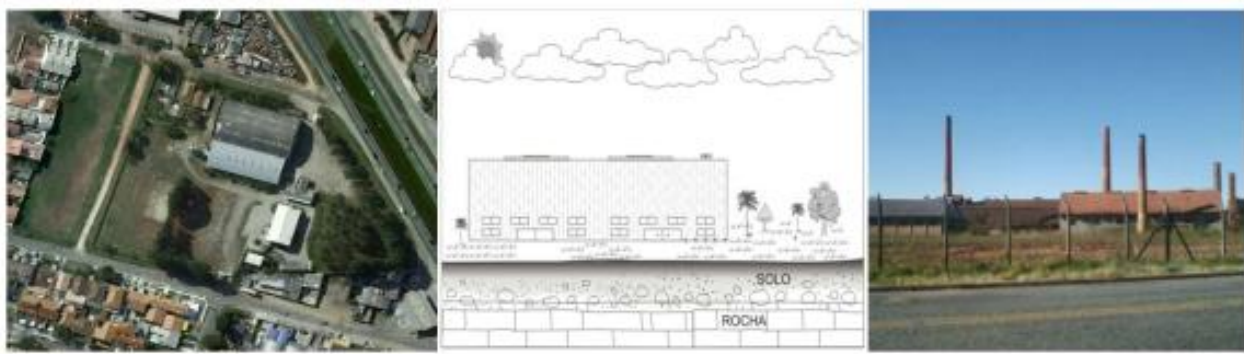

Estrutura: Galpões com aspecto industrial. Presença de vegetação que, na maioria dos casos, pertence aos estratos arbustivo e herbáceo. 0 estrato arbóreo é representado por indivíduos Dinâmica: infiltraçăo mediana da água da chuva; pouco escoamento superficial; amplitude térmica mediana; alta emissão de poluentes na atmosfera pelo tráfego de veículos incluindo os de grande porte; pouca variedade de espécies da isolados ou por grupamentos. fauna; alto gasto de energia para a manutençăo das edificações

1.9 Grandes galpões, com solo bastante impermeabilizado

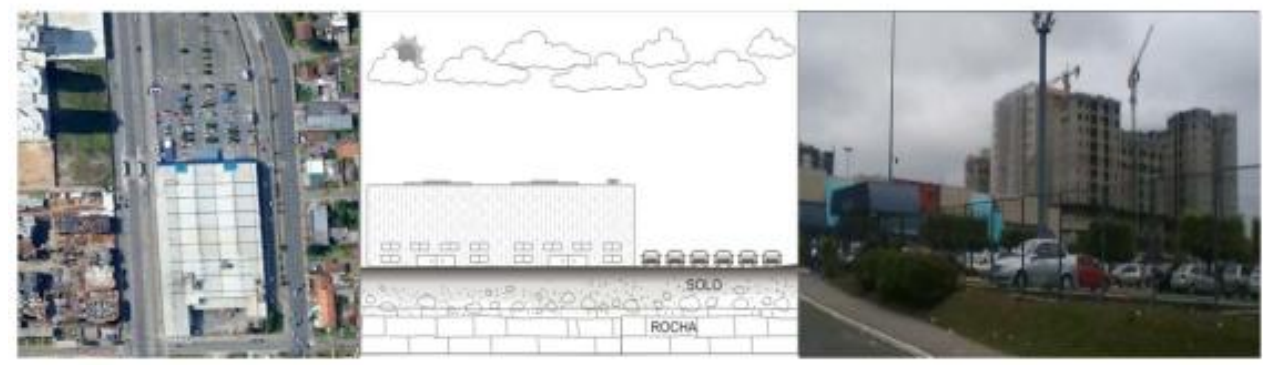

Estrutura: Galpōes com aspecto industrial. A

Dinåmica: Infiltração da água da chuva inexistente; grande vegetaçäo nos diversos estratos é pouca ou inexistente. O solo é intensamente ou totalmente impermeabilizado escoamento superficial; alta amplitude térmica; alta emissão de poluentes na atmosfera pelo trafego de veículos, incluindo os de grande porte; quase inexistência de espécies da flora e fauna; alto gasto de energia para manutenção das edificaçōes.

Figura 3c: Chave classificatória com inferências. 


\section{CLASSIFICAÇÃO DA PAISAGEM DO BAIRRO DO BACACHERI (CURITIBA, PARANÁ) COM BASE NA COBERTURA DO SOLO}

- ESPAÇOS NÃO EDIFICADOS

3.2 Praças pequenas
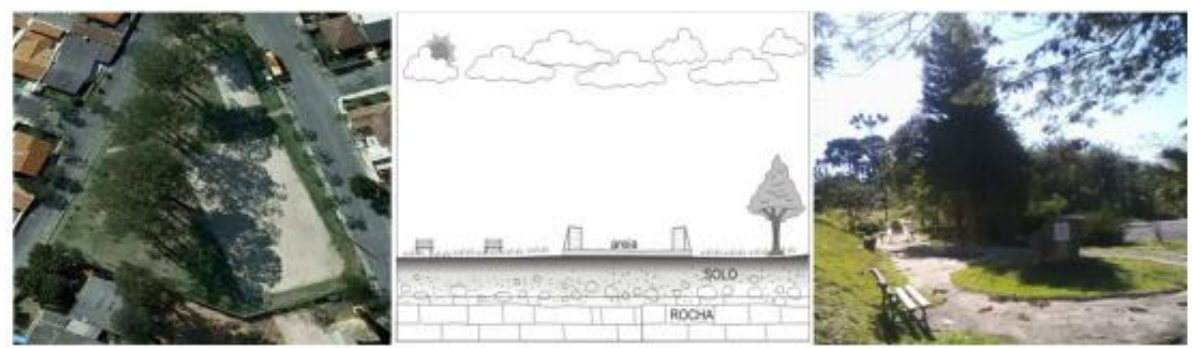

Estrutura: Praças públicas pequenas. Em alguns casos trata-se de sobra de terreno nas quadras ou às margens dos rios. Predomínio de vegetação herbácea. Podem ter Dinâmica: Infiltração mediana da água da chuva; pouco canchas de areia e/ou playground
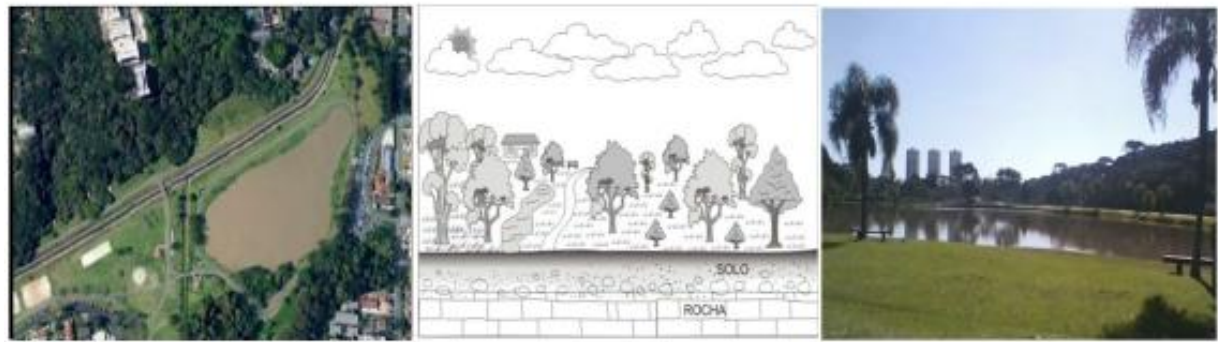

Estrutura: Parques e bosques públicos. Grande área com

Dinâmica: alta Infiltração da água da chuva;

solo permeável e presença de vegetação nos três estratos.

Possui equipamentos e espaços que estimulam a

escoamento superficial muito baixo; baixa amplitude

recreação livre. Podem ter corpos hídricos.

térmica; baixa emissäo de poluentes na atmosfera;

maior variedade de espécies da flora e fauna.

Figura 3d: Chave classificatória com inferências. 


\section{CLASSIFICAÇÃO DA PAISAGEM DO BAIRRO DO BACACHERI \\ (CURITIBA, PARANÁ) COM BASE NA COBERTURA DO SOLO}

3.8 Vegetação arbustiva e herbácea
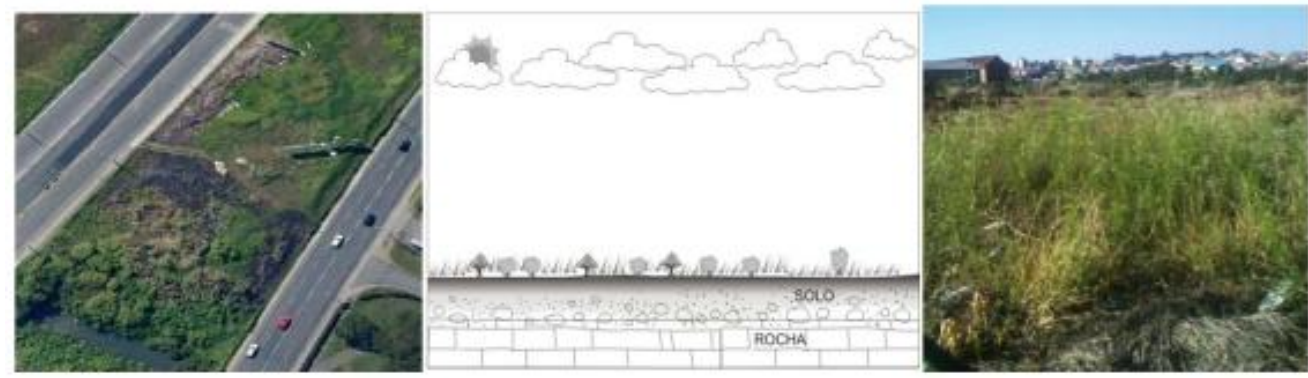

\begin{tabular}{|l|l|}
\hline Estrutura: Terreno sem edificações, permeável, & Dinâmica: baixa Infiltração da água da chuva;aumento do \\
com vegetação nos estratos arbustivo e & escoamento superficial muito baixo; aumento da amplitude \\
herbáceo. Podem ser identificadas poucas & térmica; baixa emissão de poluentes na atmosfera; pouca \\
arvores isoladas ou em grupamento muito & variedade de espécies da flora e fauna; baixa taxa de \\
pequenos. & evapotranspiração. \\
\hline
\end{tabular}

\section{TRANSPORTE}

\subsection{Aeroporto}

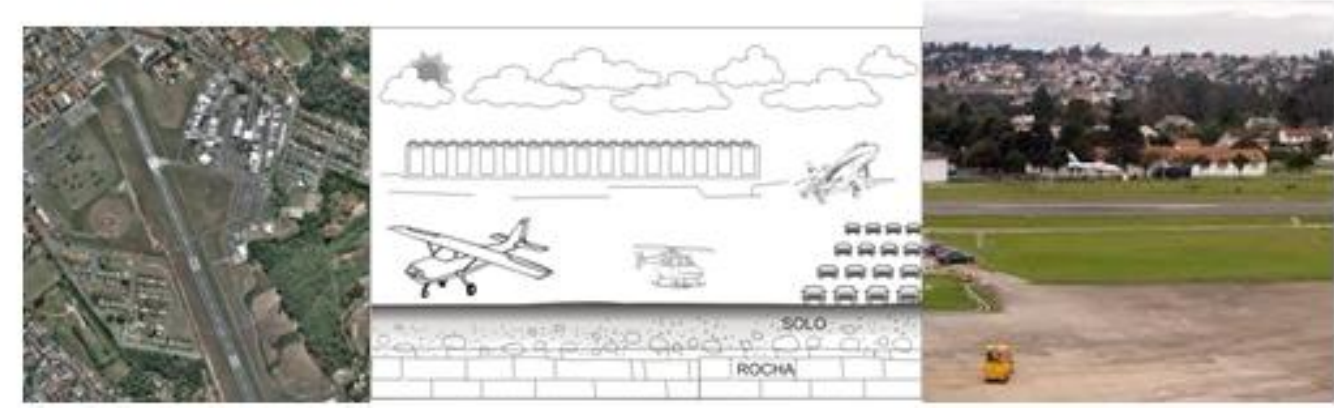

Estrutura: Edificações baixas com pouco ou nenhum espaço destinado para jardim ou horta. A vegetaçāo é praticamente inexistente, Solo intensamente

Dinâmica: infiltração da água da chuva quase inexistente; alto escoamento superficial; alta amplitude térmica; impermeabilizado.

Figura 3e: Chave classificatória com inferências.

Da tabela 2 pode-se destacar que o bairro apresenta 59,3\% de sua área ocupada por espaços edificados, 23,3\% por espaços não edificados e 17,4\% por espaços compostos por ruas e avenidas, situação inferior, porém não tão distante do que é proposto pelos setores de planejamento da Alemanha (40\%, 40\% e 20\% respectivamente).

Também, destaca-se que a área dos espaços edificados somados aos espaços viários é de $76,7 \%$, e, portanto, sobram os $23,3 \%$ para os espaços não edificados, resultados bem diferentes em relação aos valores encontrados na tabela 1, ou seja, $49 \%$ e $51 \%$ respectivamente, para a médias das cidades alemãs.

$\mathrm{Na}$ tabela 2 ainda é possível notar que a maior parte do total do bairro 


\section{CLASSIFICAÇÃO DA PAISAGEM DO BAIRRO DO BACACHERI}

(CURITIBA, PARANÁ) COM BASE NA COBERTURA DO SOLO

$(36,1 \%)$ pertencem a categoria de "edificações baixas (máximo 4 pavimentos)" e, ainda, que 32,2\% (46,6ha + 178,4ha) são constituídos por edificações baixas e com jardins ou hortas adjacentes. Esse tipo de paisagem, associada aos $23,3 \%$ de espaços não edificados e, em sua grande maioria, recobertos por vegetação, fazem do Bacacheri um bairro que possui uma boa qualidade ambiental.

Entretanto, as áreas ocupadas por paisagens com aspecto industrial, com grandes galpões, com vegetação e/ou solo impermeabilizado (cor cinza no mapa da figura 2), trazem pontualmente para o bairro uma diminuição da qualidade ambiental.

É preciso destacar que este trabalho não está analisando o uso do solo, mas sim a cobertura do solo, sendo assim, o aeroporto do Bacacheri, apesar de não ocasionar grandes problemas para a qualidade ambiental quanto a cobertura do solo, pode diminuí-la se for considerado o seu funcionamento (uso), mesmo sendo um aeroporto regional.

Os resultados, com base em imagens de 2010, se comparados aos encontrados por Pivettaet al. (2005), que analisaram fotografias aéreas de 2002, apontam que em 2002 o bairro apresentava 30,0\% (209,4ha) de áreas não edificadas (PIVETTA et al. 2005) e em 2010 esse valor passou para 23,3\% (162,5ha) (Tabela2), ou seja, em oito anos houve uma redução de 6,7 pontos percentuais ou $22,4 \%$ (46,9ha). Como as áreas das praças, parques, corpos hídricos e do aeroporto não devem ter diminuído, muito provavelmente, essa redução se deve a ocupação por edificações dos espaços antes constituídos por vegetação arbustiva e herbácea, ou seja, lote a lote, quase de forma imperceptível para quem acompanha a distância, o pouco que resta de natureza, mesmo que seja apenas em terrenos baldios, vai sendo ocupado por paisagens de concreto e verticalizadas.

\section{CONCLUSÃO/CONSIDERAÇÕES}

O trabalho teve por objetivos apresentar uma classificação das unidades de paisagem do bairro do Bacacheri (Curitiba, Paraná), do ano 2010 e com base no método de Valaski (2013) e fazer uma comparação dos resultados com os valores obtidos por Pivetta et al. (2005) para o mesmo bairro. 
O bairro do Bacacheri, em apenas oito anos, perdeu quase 47ha, possivelmente de lotes antes ocupados por vegetação arbustiva e herbácea que cederam lugar a solo impermeável e com edificações, o que sugere uma diminuição de sua qualidade ambiental.

Concluiu-se que o método desenvolvido por Valaski (2013) é de fácil execução e deve ser utilizado no planejamento e como técnica para participação popular no desenvolvimento dos municípios.

Esse método, associado às técnicas de mapeamento e quantificação dos SIGs, permite um controle e monitoramento da dinâmica e evolução de ocupação dos espaços urbanos.

Nos últimos anos, no município de Curitiba, o mercado imobiliário vem ocupandode forma intensa os espaços não edificados provocando um crescimento das construções de edifícios que se distribuem por toda a cidade.

Espera-se que os trabalhos de classificação, mapeamento e quantificação dos espaços urbanizados possam, de alguma forma, alertar e instruir a população em relação a essa perda da qualidadeambiental que ocorrem nas cidades.

\section{AGRADECIMENTOS}

Os autores agradecem o apoio financeiro do CNPq pela concessão da bolsa de produtividade em pesquisa ao segundo coautor.

\section{REFERÊNCIAS}

BELEM, A.L.G.; NUCCI, J.C. Hemerobia das paisagens: conceito, classificação e aplicação no bairro Pici - Fortaleza-Ce. RA'E GA, Curitiba, n. 21, 204-233p. 2011.

BERLIM. Senate Departament of Urban Development. Berlin Digital Environmental Atlas. Actual Use of Built-up Areas. Disponível em: www.stadtentwicklung.berlin.de/umweltatlas/ed601 05.htmAcesso em: 14.07. 2001.

BUCCHERI FILHO, A.T. O planejamento dos parques no munícipio de Curitiba, Pr: planejamento sistemático ou planejamento baseado em um modelo oportunista? Caminhos de Geografia, Uberlândia, v. 13, n. 41, 206-222p. mar/2012. 
BUCCHERI FILHO, A.T.; NUCCl, J.C. Espaços livres, áreas verdes e cobertura vegetal no bairro Alto da XV, Curitiba/PR. Revista do Departamento de Geografia/USP, n. 18, 48-59p. 2006.

BRASIL. Constituição da República Federativa do Brasil. 1988. Disponível em: http://www.planalto.gov.br/ccivil 03/constituicao/constituicaocompilado.htm Acesso em: 08.03.2014.

GRÖNING, G. Felisberto Cavalheiro e um exemplo de cooperação Brasil-Alemanha na cultura de jardins e desenvolvimento de espaços livres. In: SANTOS, D.G. doseNUCCI, J.C. (eds.) Paisagens Geográficas: um tributo à Felisberto Cavalheiro. Campo Mourão: FECILCAM, 10-17p. 2009.

IPPUC. Instituto de Pesquisa e Planejamento Urbano de Curitiba. Disponível em: www.ippuc.org.br Acesso em: 01.10.2013.

JACKSON, L.E. The relationship of urban design to human health and condition. Landscape and Urban Planning, London, n. 64, 191-200p. 2003.

KIEMSTED, H.; von HAAREN, C.; MÖNNECKE, M.; OTT, S. Landscape Planning: contents and procedures. Hanover: The Federal Ministry for the Environment, Nature Conservation and Nuclear Safety, University of Hanover, 39p. 1998.

$\mathrm{NUCCl}$, J.C. Origem e desenvolvimento da Ecologia e da Ecologia da Paisagem. Revista Eletrônica Geografar, Curitiba, v. 2, n. 1,77-99p. 2007.

$\mathrm{NUCCl}$, J.C. Análise sistêmica do ambiente urbano, adensamento e qualidade ambiental. Revista PUC SP Ciências Biológicas e do Ambiente, São Paulo, v. 1, n.1, 73-88p. 1999.

$\mathrm{NUCCI}$, J.C. Metodologia para determinação da qualidade ambiental urbana. Revista do Departamento de Geografia (USP), São Paulo, v. 10, n.12, 209-224p. 1998.

PAULEIT, S.; DUHME, F. Assessing the environmental performance of land cober types for urban planning. Landscape and Urban Planning, London, n.52. 1-20p. 2000 .

PIVETTA, A.; CARVALHO, J.A.; DALBEM, R.P.; MOURA, A.R; NUCCI, J.C. Sistema de classificação da cobertura do solo para fins de comparação entre cidades e bairros. Anais do XI Simpósio Brasileiro de Geografia Física Aplicada. São Paulo: DG-USP, 2005. 
SUKOPP, H; BLUME, H.P.; KUNICK, W. The soil, flora and vegetation of Berlin's waste lands. In: Laurie, I.C. (Ed.): Nature in cities. Wiley, Chichester, 1979.

TONETTI, E.L.; NUCCI, J.C.; VALASKI, S. Espaços livres na área urbana de Paranaguá (Paraná, Brasil). Revista da Sociedade Brasileira de Arborização Urbana, Piracicaba, v. 7, 37-50p. 2012.

VALASKI, S. Estrutura e Dinâmica da Paisagem: subsídios para a participação popular no desenvolvimento urbano do município de Curitiba. Tese de doutorado (Programa de Pós graduação em Geografia - UFPR), Curitiba, 2013. 